\title{
Research
}

\section{Use of the Mother Tongue in Teaching a Foreign Language}

\author{
Tsafi Timor \\ Kibbutzim College of Education, Technology and the Arts, Israel
}

\begin{abstract}
This article addresses the controversy around teacher use of the mother tongue (MT) in foreign language (FL) teaching. Empirical and theoretical knowledge advocates that the MT should be incorporated by teachers in FL classrooms. The present study was conducted among 112 English language teachers in Hebrew-speaking elementary and secondary schools in Israel. The research tool was a questionnaire designed specifically for the purpose of the study. Findings demonstrate that teachers' overall attitude towards MT use in FL classrooms is positive; they report using the MT for teaching purposes and a small number use the MT for classroom management purposes. Elementary and secondary school teachers differ in their use of the MT. Findings may be useful to language education policy-makers in designing more formal and concrete guidelines to help FL teachers use students' MT judiciously. The article offers a model for an efficient use of the MT in FL classrooms.
\end{abstract}

The question whether the students' mother tongue (MT) should be used in English as a Foreign Language (EFL) classrooms in Israel has been re-opened to controversy recently, after many years in which the MT was discouraged on pedagogical grounds in the teaching of foreign languages (FL). This situation exists in many other countries where English as a foreign language (EFL) is taught, given the processes of globalization worldwide, e.g., German as the MT in EFL lessons in German schools or Thai as the MT in EFL classrooms in Thailand. In the state of Israel, it was difficult in the past for teachers to incorporate Hebrew as the MT into EFL classrooms for two reasons: (a) Israel was founded by Jews who immigrated to Israel from all parts of the world; thus, many English teachers were newcomers and did not speak Hebrew themselves, and (b) classes were characterized by a multiplicity of MTs. However, later, when Hebrew became a commonly spoken language for more teachers and students alike, teachers often avoided using it in teaching because it was considered pedagogically inappropriate.

In Israel, EFL lessons start in Grade 2 or 3 of elementary school. Although most secondary school graduates speak English at different levels and may be exposed to English on the Internet and television, English is rarely heard or spoken on the streets.

This article addresses the controversy that revolves around the pedagogical appropriateness of teacher usage of students' MT in FL teaching. It presents findings from a study conducted

Language Education in Asia, 2012, 3(1), 7-17. http://dx.doi.org/10.5746/LEiA/12/V3/I1/A02/Timor 
among English teachers in a Hebrew-speaking environment: elementary and secondary schools in Israel.

\section{Literature Review \\ Change of Attitudes Over Time Towards the Use of the MT}

For over 120 years, the prevailing attitude in FL teaching has been anti-MT and discouraging of the use of students' MT in language teaching (Cook, 2001). The main principle of FL teaching was monolingual or intra-lingual, rather than cross-lingual (Cook, 2001). The prevailing method of instruction was the Direct Method, which did not encourage the use of comparative analysis between the MT and the FL. MT-free lessons were a "badge of honor" (Butzkamm \& Caldwell, 2009, p. 24). Translation had pejorative overtones in teaching and was often avoided. Only more recently have researchers concluded that "translation provides an easy avenue to enhance linguistic awareness" (Cook, 2001). They recognized the importance of comparative analysis between the MT and the FL and that the FL does not aim at substituting for the MT. This paradigm shift to the Linguistic Interdependence Hypothesis has occurred recently (Butzkamm \& Caldwell, 2009; Cummins, 2007) and indicates a welcoming attitude to teacher usage of students" MT in teaching. However, in practice, the "judicious and principled use" of MT (Turnbull, 2001, p. 536) remains an unresolved issue; teachers often feel guilty for straying from the path of teaching using only the FL and feel the use of the MT is professionally inappropriate (Littlewood \& Yu, 2011; Swain, Kirkpatrick, \& Cummins, 2011).

An example of how attitudes have changed over time can be seen in the English Curriculum for All Grades (Spolsky, Ben Meir, Inbar, Orland, Steiner, \& Vermel, 2001), which refers to the usage of MT as an integral part of English language education. The curriculum consists of "four domains of language abilities and knowledge: social interaction, access to information, presentation [of information], and appreciation of literature, culture, and language" (p. 8). Appreciation of language in particular "is based on the principle that learning a new language provides an ideal opportunity to become aware of the nature of language, how languages are structured, and the differences between languages" (p. 11). Thus, students can develop awareness into their own MT by the teacher's use of their MT in teaching EFL. Despite changes in attitude, the present curriculum does not provide clear-cut instructions with regard to the acceptable extent of teacher use of students' MT.

\section{Arguments Against Teacher Use of Students' MT in FL Classes}

Arguments against teachers using students' MT are mainly pedagogically based. Turnbull (2001), in his response to Cook (2001), mentions that students do not benefit when teachers over-rely on using their students' MT, particularly when the EFL teacher is the sole linguistic model and main source of FL input. Classroom situations can create various experiences for students such as real-life situations through simulations (McDonald, 1993); if the teacher uses the MT to a great extent, students may lose the chance to benefit from these situations. In addition, teachers who overuse their students' MT deprive these learners of an important language process in which students try to make sense of what is being said in class (Ellis, 1994). The use of the FL in class influences students' achievements and proficiency in FL because of the experiences they gain in class.

In addition to pedagogical factors, followers of the monolingual principle support the compartmentalized language pedagogy that inhibits the interdependent nature of the MT and the FL. Hence, they perceive the introduction of the MT in FL teaching as an inhibitive factor. The three assumptions of the monolingual principle in FL teaching as reflected in Howatt's (1984) history of teaching EFL are: (a) FL teaching should be done exclusively in the FL; (b) 
translation between the MT and the FL should be avoided; and (c) in bilingual programs, the two languages should be kept separate.

\section{Arguments in Favor of Teacher Use of Students' MT in FL Classes}

The issue of teacher use of students' MT in FL teaching has been explored with a variety of languages and mainly relates to the Linguistic Interdependence Hypothesis, to universal principles of foreign language acquisition, and multi-linguistic models. Studies on the transfer between the MT and the FL indicate a linguistic interdependence (Jessner \& Cenoz, 2000) with regard to multiple subsystems (phonological, syntactic, semantic, and textual) within the MT and FL systems (Herdina \& Jessner, 2002). Bouvy (2000) supported the theory of crosslinguistic transfer with regard to literacy skills. Similarly, Hauptman, Mansur, and Tal (2008) used a trilingual model for literacy skills among Bedouins in Israel whose MT is Arabic and found that it "created a support system for Arabic, the mother tongue, through English [FL] and Hebrew [MT2]." Other researchers stated that the MT catalyzes the intake process of the FL (e.g., Ellis, 1994), as well as saves time and enhances understanding (Turnbull, 2001). Cook argued that a "systematic use" (2002, p. 403) of the MT would minimize the guilty feelings of teachers when using their students' MT. Cook (2002, p. 23) also argued that "given the appropriate environment, two languages are as normal as two lungs."

A number of psycho-linguistic arguments contribute to the stance that advocates teacher use of students' MT:

1. Teacher use of the MT cannot present a threat to FL acquisition because learners already have a language basis from their MT. Because of this basis, learners are more socially developed and have more short-term memory capacity and more maturity when they become acquainted with the FL (Cook, 2002). Therefore, there is no competition between their MT and FL.

2. The belief in the 20th century was that the MT and the FL make distinct systems in the brain. However, evidence shows that languages are interwoven in the brain in vocabulary, syntax, phonology, and pragmatics. Therefore, FL teaching should match the invisible processes in the brain and should not be separated from the MT, assuming that the ability to transfer between languages (code-switch) is a normal psycho-linguistic process (Cook, 1996; 1997).

3. The process of foreign language acquisition involves cognitive, social, and emotional factors that are inseparable and equally related to the MT and the FL.

It seems then that the sole use of the FL by the teacher is not justified theoretically or practically.

\section{Implementation}

While advocating the use of the MT in FL teaching, it is important to note that there are no criteria with regard to the right dosage of the use of the MT. Quite often teachers feel at a loss and decide to avoid using the MT altogether because they fear this will contradict the stance supervisors and headmasters take. Cook (2001) presents criteria for the judicious use of the MT: efficiency, learning, naturalness, and external relevance. Efficiency relates to doing something more effectively through the MT. Learning concerns whether FL learning is enhanced by the use of the students' MT. Naturalness relates to whether students prefer the use of their MT rather than the FL regarding certain topics. Finally, external relevance is whether the MT helps students with uses of the FL they may need beyond the classroom. The last criterion may be associated with the use of English for communication purposes; it may refer to 
everyday topics, life skills, and pragmatic language such as conversing or participating in online chats in English.

Although these criteria may be useful to clarify the general teaching circumstances for using the MT with regard to a certain class or topic, they certainly cannot substitute for formal guidelines that should be defined practically and in terms of specific topics, situations, and frequency. Examples for such guidelines could be "while teaching tenses that exist in the student's MT, you may use comparisons to facilitate understanding" or "avoid literal translations and try synonyms or pictures instead." The use of clear instructions may reduce teachers' feelings of anxiety and guilt, and legitimize the use of the MT to a certain extent.

The language areas for which teachers would prefer to use the MT should also be considered. Previous studies indicate that teachers use the MT in EFL classrooms to explain new vocabulary and grammatical structures (Cook, 1997), organize tasks and give instructions (Cook, 2001), and maintain discipline in class and create rapport with individual students (Macaro, 1997).

\section{Goal of the Study}

The study focuses on the examination of English teachers' attitudes and ways of implementing the MT in EFL teaching in elementary and secondary schools in Israel. EFL teachers' attitudes will be explored as part of the abovementioned paradigm shift. Findings will demonstrate what pedagogical stance teachers in Israel take with regard to Hebrew as the MT in EFL classes.

After understanding teachers' attitudes, the study will attempt to explore whether there are gaps between attitudes and implementation. Findings will exemplify more concretely the situations and topics in which teachers feel that the use of the MT will facilitate the learning and teaching process.

As the study comprises two populations of teachers, a comparison will be made. Findings will allow for the identification of differences between elementary and secondary school teachers. The findings will also enable supervisors of language education and decision-makers to design formal guidelines that will help teachers use the MT in a balanced and effective manner.

\section{Methodology}

The participants in this study were 112 randomly selected EFL teachers in Israel: sixty elementary school teachers (EST), and fifty-two secondary school teachers (SST). All are speakers of Hebrew and have more than five years of teaching experience. Their ages range from 35 to 55 . The research tool was a questionnaire that included seven questions (Timor, 2010). The first two questions related to teachers' attitudes with regard to the use of Hebrew as the MT in EFL teaching, and the remainder of the questions related to implementation issues (frequency of use, grammatical topics, language areas, and other uses). The comparison between the two groups of teachers was conducted with reference to all questions.

Three of the questions $(1,2,3)$ are on a Likert Scale. Whereas in Questions 1 and 3 the score of 1 indicates an anti-MT attitude and the score of 5 indicates a pro-MT attitude, in Question 2, the score of 1 indicates a pro-MT attitude and the score of 5 indicates an anti-MT attitude. Three questions are multiple-choice (4, 5, and 6), and four are open-ended (1, 2, 5, and 7). Questions 1, 2, and 5 provide both a multiple choice / Likert part and an open-ended part. The full questionnaire can be found in the appendix. Findings were calculated and are presented in percentages. 


\section{Findings}

\section{Question 1: Arguments for MT Use in EFL Teaching}

The teachers' answers indicate that they can see the benefit of using the MT in English lessons (EST, 100\%; SST, 87\%). When asked to explain their reasons, teachers brought up the following arguments:

- "The MT helps me to explain complicated issues."

- "Young learners in lower grades demonstrate limited understanding of English. I find that when I speak in English and they don't understand what I am saying, they mentally zone out, so a good mix of the FL and MT is useful to keep them going."

- "Weaker students will be discouraged and frustrated if I do not use their MT; for them it is easier to understand grammar and vocabulary when they get an additional explanation in their MT."

- "Explanations can be more thorough in the MT."

- "Explanations in the MT provide confidence."

- "Explanations in the MT save time."

- "In many cases the use of the MT clarifies issues in the shortest and most efficient way."

- "Because of the overpopulated (42 pupils), heterogeneous classes, the use of the MT is a must, or else my weak pupils will become disruptive."

- "The MT reduces anxiety among students with learning disorders."

\section{Question 2: Arguments Against MT Use in EFL Teaching}

Only $13 \%$ of SST are against the use of the MT in teaching EFL. When asked why, teachers responded with the following arguments:

- "If I make more efforts to prepare teaching aids, students can understand me without using the MT."

- "If the need arises, I will make the students use the MT rather than myself."

- "We should always explain in English, only if there is no other choice we should switch to the MT."

- "Teachers should be committed to the FL in their teaching although students will always try to drag them into using the MT."

- "All immersion programs advocate the use of the FL in order to upgrade students' knowledge."

- "Once the teacher starts using the MT, there is no way back."

- "The use of the MT slows down the process of learning."

\section{Question 3: Frequency of MT Use in EFL Teaching}

More than half of the EST and SST ranked the frequency of their use of the MT as average (3 on the scale): $65 \%$ and $62 \%$ respectively. The lower reports of frequencies ( 2 on the scale) were observed among SST (32\%), more than among EST (15\%). The higher reports of frequencies (4 and 5 on the scale) were observed among EST (20\%), more than among SST (6\%).

\section{Question 4: MT Use for Grammatical Structures Not Found in the MT}

Most teachers use the MT to teach grammatical structures that do not coincide between the MT and FL (EST, 70\%; SST, 75\%). The examples teachers provided for structures that exist in English but do not exist in Hebrew were the present perfect, present progressive, and past progressive, or structures that have specific rules in English, such as back-shifting in reported speech. 


\section{Question 5: MT Use in Teaching Grammar}

Both EST and SST report using the MT to a great extent in grammar teaching: EST use the MT mostly to teach simple tenses $(75 \%)$, modals $(29 \%)$, and comparative forms $(16 \%)$; SST use the MT to teach complicated tenses $(87 \%)$, modals $(63 \%)$, conditionals $(56 \%)$, relative clauses $(44 \%)$, reported speech $(44 \%)$, and phrasal verbs $(25 \%)$.

\section{Question 6: MT Use in Teaching Language Skills}

SST report using the MT to teach vocabulary $(75 \%)$, reading comprehension $(25 \%)$, and writing skills $(18 \%)$. EST also use the MT to teach vocabulary (79\%), reading comprehension skills (54\%), and writing skills (33\%).

\section{Question 7: Other MT Uses in FL Teaching}

Other cases exist in which teachers make use of Hebrew as the MT. SST use it when they need to explain complex issues, give instructions, handle discipline problems, or explain grammar rules; EST use the MT to explain complex issues, teach learning habits, give instructions, or handle discipline. Both groups use the MT to create rapport with individual students.

\section{Discussion}

This article revolves around the question of whether or not the MT should be "brought back from exile" (Cook, 2001, p. 419). It aims at the examination of English teachers' attitudes and ways of implementation with regard to the use of Hebrew as the MT in EFL teaching in elementary and secondary schools in Israel. This was done by conducting a study among EFL teachers and presenting their attitudes and practical implementation regarding the use of Hebrew as the MT in class. Findings demonstrate that teachers' attitudes are positive and most of them see the benefit of using the MT in EFL teaching. Both EST and SST clearly saw the benefit in the use of Hebrew as the MT in the English classroom and only $13 \%$ of SST objected to it. At the same time, it seems that the use of the MT is moderate among both EST and SST (65\% and $62 \%$ respectively). In addition, the higher frequencies of use of the MT were found among EST, whereas the lower frequencies were found among SST. These findings support Cook's (2001) criterion of "learning," indicating that teachers' attitudes may derive from their experience that the introduction of the MT in EFL classes enhances learning.

Teachers reported using Hebrew mainly for structures that do not coincide with structures of English. This may be accounted for by the fact that it is more difficult to explain structures that do not exist in one's MT, so the use of the MT might facilitate understanding. For example, in Hebrew, there is one present tense and one past tense, whereas in English there are four present tenses (present simple, present progressive, present perfect, present perfect progressive) and four past tenses (past simple, past progressive, past perfect, past perfect progressive). Another example is reported speech, which is difficult for speakers of Hebrew because the rules of back-shifting in time and place do not exist in Hebrew. It is noteworthy that both EST and SST use the MT for structures that do not coincide between English and Hebrew. These findings support Cook's (2001) criterion of efficiency, indicating that some topics can be taught more effectively through comparisons to the MT.

SST use the MT for more grammatical structures than EST, because the structures taught in secondary schools, according to the English Curriculum for All Grades (Spolsky et al., 2001), are more numerous and complex (e.g., complicated tenses, conditionals, modals). Students in secondary schools are more capable of writing in English and must meet standards for graduation. Therefore, it is quite surprising that both SST and EST reported the use of the MT to teach vocabulary to almost the same extent (75\% and $79 \%$ respectively). Obviously, teachers 
referred to different levels of vocabulary, and SST possibly referred to idioms and figurative language, which may explain the findings.

The following example further advocates the use of the MT in EFL teaching with regard to vocabulary and also clearly demonstrates the relationship between language and culture: an EFL teacher needs to teach the idiom "making a mountain out of a molehill," which has an equivalent in Hebrew: "making an elephant from a fly." If the teacher is able to provide the equivalent idiom in the students' MT, it will facilitate the explanation, which, in this case, requires higher language skills and an understanding of figurative language. The obvious relationship between language and culture that needs to be set in language lessons is sometimes neglected for reasons of ethics or pedagogical inappropriateness. However, this methodology might help students benefit from the comparison of the idiom in English and their MT. In this case, the MT should be considered an enabling factor because it enhances understanding in a quick, efficient way, and does not present an ethical issue at all. Therefore, the belief that the use of the MT in FL classrooms should be discouraged might be limiting rather than enabling language learning.

A small number of teachers report on relying on the MT for a variety of classroom management situations as well, such as setting rapport with an individual student, giving instructions, or handling discipline problems. These findings make sense because it might sound artificial to use the FL to scold when both the teacher and the student have the same MT. These findings agree with Cook's (2001) criterion of naturalness as well as that of other researchers, by indicating that the student would feel more at ease in their MT with regard to certain classroom activities (e.g., Brooks \& Donato, 1994).

\section{Conclusion}

The contributions of this study are threefold:

Firstly, it offers an updated picture of this controversial issue: the findings demonstrate a positive pedagogical stance teachers in Israel take with regard to Hebrew as the MT in EFL classes, and reveal that the MT is used for teaching topics in EFL such as grammatical issues or reading comprehension, and in a small number of cases, for specific classroom management situations.

Secondly, this study helps in paving the way onwards: the findings show that teachers already use Hebrew as the MT with an average to high frequency and for different purposes in the classroom, but do so with guilt feelings of almost "cheating the system." This situation calls for an urgent need to devise standards and formal guidelines for using the MT in FL classrooms by ministries of education and policy-makers. However, until guidelines are provided, in meetings with supervisors or subject coordinators, FL teachers should advocate for the MT as a teaching tool in classroom practice by indicating that using the MT works. They should argue that the use of the MT saves time and enhances understanding, particularly among slow learners, and that comparisons between the two languages enhance understanding about how languages "behave." This will eventually move the discussion toward greater acceptance of the MT by policy-makers who rely on theories and worldwide trends, but also on teaching practices.

Finally, the study suggests a model that depicts the link between the MT and the FL on a continuum (Figure 1). Whereas in earlier times, professionals strongly discouraged the use of the MT in class altogether (Option 1), minimized it (Option 2), and advocated a maximum use of the $\mathrm{FL}$, the present study advocates enabling the use of the MT at different degrees 
depending on circumstances (Option 3), but at the same time maximizing the use of the FL. Circumstances include the level of class, the goals of teaching, learners' age and motivation. Of course, unlimited use of the MT by the teacher should not be considered a feasible option because it clearly contradicts the objectives of teaching FL. It is recommended that further research be conducted on a larger number of participants and dwell on the more specific differences between EST and SST, so that more specific guidelines could be designed for them.

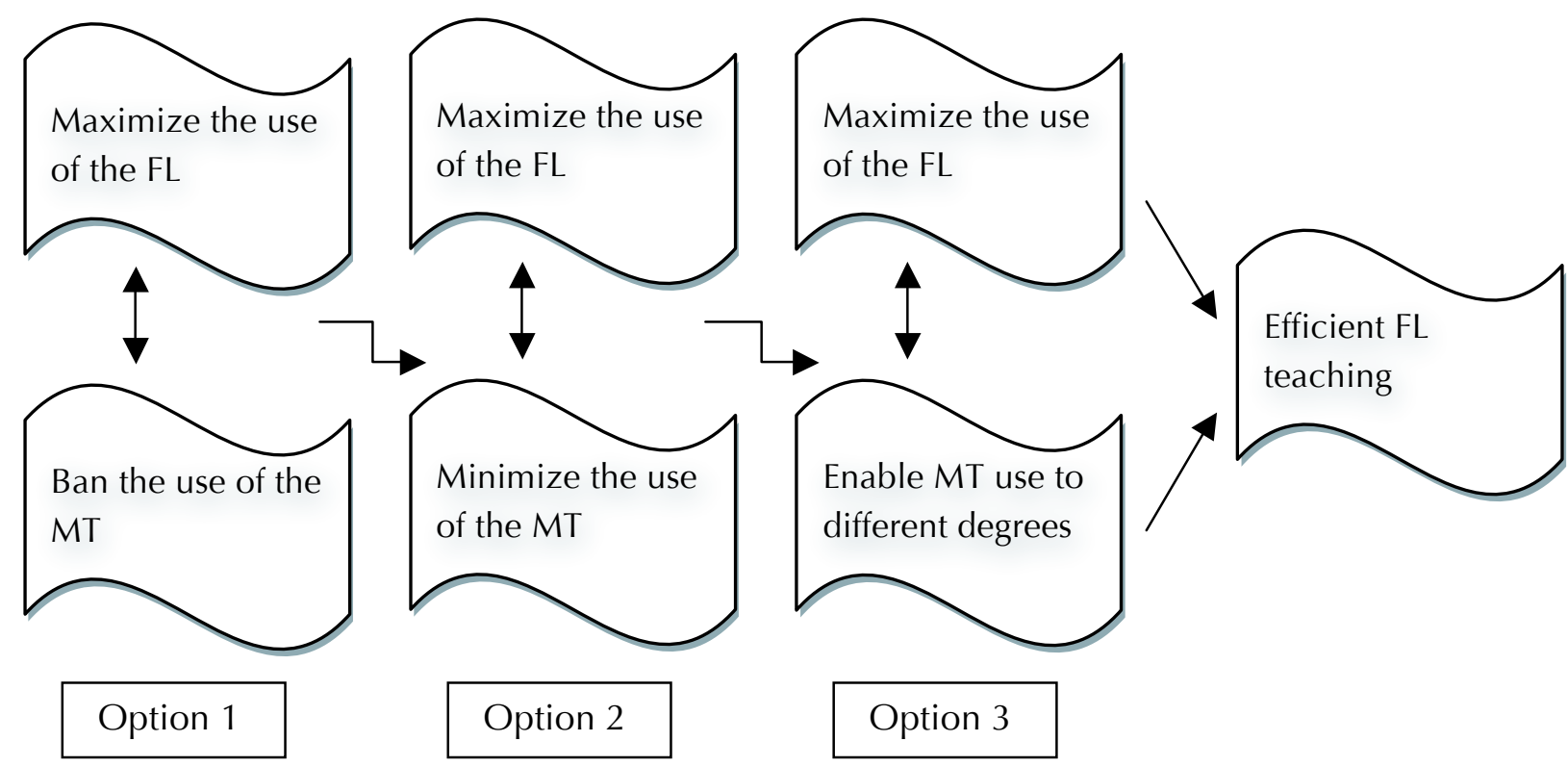

Figure 1. The continuum of use of the MT in FL teaching

Since updated research and brain theories as well as classroom reality welcome the MT in FL classrooms, it is high time that FL teachers realize that they do not "betray" their mission and profession by introducing the MT into their classes. The MT is an important asset that facilitates FL teaching, and teachers must understand that a broad exposure for students to the FL does not justify a ban of the use of the MT in teaching the FL. The present study supports the stance that the combination of the already existing positive attitudes of EFL teachers coupled with clear guidelines by policy-makers will lead to a systematic "front-door use" rather than the former "back-door use" of the MT in teaching foreign languages.

\section{Author Note}

Tsafi Timor, English Language Education Department, Program for Postgraduate Diploma in Education, Kibbutzim College of Education, Israel.

Correspondence concerning this article should be addressed to Tsafi Timor, English Language Education Department, Kibbutzim College of Education, 149 Namir Road, Tel-Aviv, Israel. Email: tsafit@bezeqint.net 


\section{References}

Bouvy, C. (2000). Towards the construction of a theory of cross-linguistic transfer. In J. Cenoz \& U. Jessner (Eds.), English in Europe: The acquisition of a third language (pp. 143-155). Clevedon, England: Multilingual Matters.

Brooks, F. B., \& Donato, R. (1994). Vygotskyan approaches to understanding foreign language discourse during communicative tasks, Hispania, 77(2), 262-274. http://dx.doi.org/10.2307/344508

Butzkamm, W. \& Caldwell, J. (2009). The bilingual reform: A paradigm shift in foreign language teaching. Tübingen, Germany: Gunter Narr Verlag.

Cook, V. (2001). Using the first language in the classroom. The Canadian Modern Language Review, 57(3), 402-423. http://dx.doi.org/10.3138/cmlr.57.3.402

Cook, V. J. (1996). Second language learning and language teaching $\left(2^{\text {nd }}\right.$ ed.). London, England: Edward Arnold.

Cook, V. J. (1997). The consequences of bilingualism for cognitive processing. In A. M. B. de Groot \& J. F. Kroll (Eds.), Tutorials in bilingualism: Psycholinguistic perspectives (pp. 279-299). Hillsdale, NJ: Lawrence Erlbaum.

Cook, V. J. (Ed.). (2002). Portraits of the L2 user. Clevedon, England: Multilingual Matters.

Cummins, J. (2007). Rethinking monolingual instructional strategies in multilingual classrooms. Canadian Journal of Applied Linguistics, 10, 221-240.

Ellis, R. (1994). The study of second language acquisition. Oxford, England: Oxford University Press.

Hauptman, S., Mansur, F., \& Tal, R. (2008). A trilingual teaching model for developing academic literacy skills in classical Arabic (L1), Hebrew (L2) and English (FL) in southern Israel. Journal of Multilingual and Multicultural Development, 29(3), 181-197. http://dx.doi.org/10.1080/01434630802147601

Herdina, P., \& Jessner, U. (2002). A dynamic model of multilingualism: Perspectives of change in psycholinguistics. Clevedon, England: Multilingual Matters.

Howatt, A. (1984). A history of English language teaching. Oxford, England: Oxford University Press.

Jessner, U., \& Cenoz, J. (2000). Expanding the score: Sociolinguistic, psycholinguistic and education aspects of learning English as a third language in Europe. In J. Cenoz \& U. Jessner (Eds.), English in Europe: The acquisition of a third language (pp. 248-260). Clevedon, England: Multilingual Matters.

Littlewood, W. \& Yu, B. (2011). First language and target language in the foreign language classroom. Language Teaching, 44(1), 64-77.

http://dx.doi.org/10.1017/S0261444809990310

Macaro, E. (1997). Target language, collaborative learning and autonomy. Clevedon, England: Multilingual Matters.

McDonald, C. (1993). Using the target language. Cheltenham, UK: Mary Glasgow.

Spolsky, B., Ben Meir, D., Inbar, O., Orland, L., Steiner, J., \& Vermel, J. (2001). English curriculum for all grades: Principles and standards for learning English as a foreign language in Israeli schools. Jerusalem, Israel: Ministry of Education.

Swain, M., Kirkpatrick, A., \& Cummins, J. (2011). How to have a guilt-free life using Cantonese in the English class: A handbook for the English language teacher in Hong Kong. Hong Kong: Research Center into Language Acquisition and Education in Multilingual Societies, Hong Kong Institute of Education. http://repository.ied.edu.hk/dspace/handle/2260.2/11955

Timor, T. (2010, June). The use of Hebrew as mother tongue in the acquisition of EFL. Paper presented at the Bloomsbury Round Table on Communication, Cognition and Culture: The Multiple Faces of Multilingualism, Birkbeck, University of London, England. 
Turnbull, M. (2001). There is a role for the L1 in second and foreign language teaching, but? The Canadian Modern Language Review, 57(4), 531-535.

http://dx.doi.org/10.3138/cmlr.57.4.531 


\section{Appendix \\ Questionnaire}

(Timor, 2010)

\section{The Use of Hebrew as the MT Among EFL Teachers}

Dear Teacher, the questions below refer to the use of Hebrew as a mother tongue in EFL teaching. In questions on the scale of 1-5, 1 means strongly disagree, whereas 5 means strongly agree. Your opinion is highly appreciated.

1. I can see the benefit of using Hebrew in EFL teaching $1 \begin{array}{lllll}1 & 2 & 3 & 4 & 5\end{array}$ (circle relevant answer) mainly because

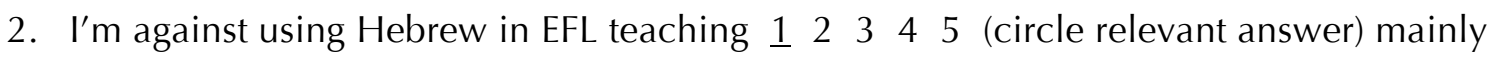
because

3. I refer to Hebrew in my EFL teaching $\begin{array}{lllllll}1 & 2 & 3 & 4 & 5\end{array} \quad(1$ = quite rarely; 5 = quite frequently).

4. I refer to Hebrew mainly when structures in English and Hebrew coincide / do not coincide (please circle relevant answer).

5. I refer to Hebrew when I teach the following grammatical topics (please circle relevant answers and specify):

Tenses (which ones?)

Relative Clauses (which ones?)

Comparative Forms (which forms? "as...as" "...er than" "the ...est")

Reported Speech (reported questions? negations? statements?)

Phrasal Verbs (e.g.,

Modals (which ones?)

\section{Conditionals}

\section{Other}

6. I refer to Hebrew when I teach vocabulary / reading comprehension skills / writing skills / other (circle relevant answers)

7. I use Hebrew in the following cases in my EFL teaching

Thanks a lot for your input! 